\section{EXPERIMENTAL ENDOCARDITIS}

ITS PRODUCTION WITH STREPTOCOCCUS VIRIDANS OF LOW VIRULENCE *

H. K. DETWEILER, M.D.

Junior Research Fellow; Instructor in Bacteriology, University of Toronto, Faculty of Medicine

AND

W. L. ROBINSON, B.A., M.B. Pathologist, Toronto General Hospital TORONTO, ONTARIO

In October, 1915, there was reported from this laboratory and the department of medicine, ${ }^{1}$ results obtained by the special methods of Rosenow in connection with an investigation into the bacteriology of the blood in a form of endocarditis less severe than the type commonly called subacute bacterial endocarditis, and in many cases milder even than those commonly recognized as simple endocarditis. We promised at that time to publish an account of the characteristics of the organisms recovered, and their action on animals. In the pursuit of this work we were hampered greatly by the special conditions made necessary by the exigencies of the war, particularly in regard to the depletion of the staff of the laboratory in response to the call to overseas service. Many phases of the work, therefore, have been allowed to remain untouched until time permits of their further investigation; but sufficient data are at hand to warrant the publication of our findings.

In following out the methods advocated by Rosenow ${ }^{2}$ we have elaborated a technic which has been used for some time and which has given splendid results. Thirty c.c. of blood are withdrawn into a record syringe which has previously been sterilized and loaded with 5 c.c. of sterile 2 per cent. sodium citrate solu-

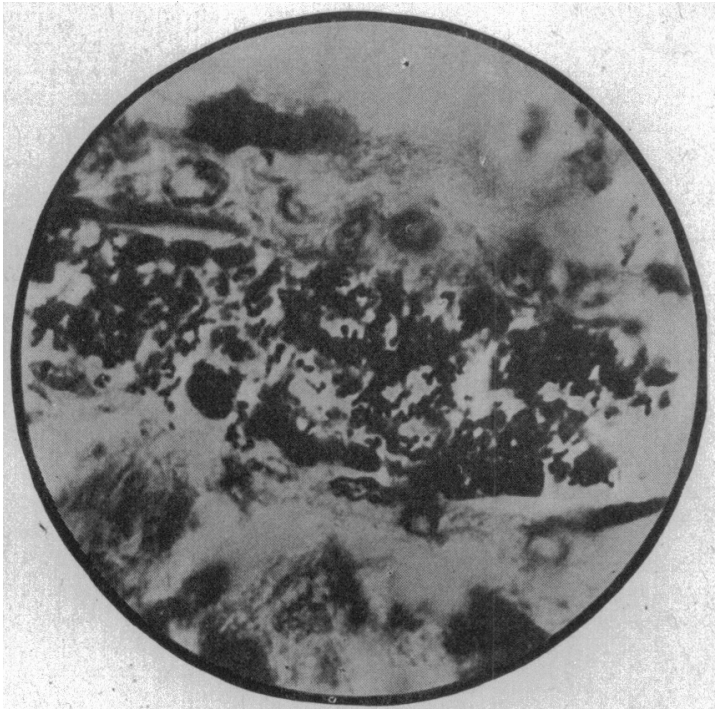

Fig. 1 (R. 517).--Bacteria growing in blood vessel of the myocardium

tion in normal saline. By inverting the syringe several times a thorough mixture is secured and clotting thereby prevented. The citrated blood is directly

* Lack of space has prevented the inclusion of all the cases in this article as it appears in THE Journal. They will be included in the reprints, a copy of which may be obtained on application to the authors.

1. Oille, J. A.; Graham, Duncan, and Detweiler, H. K.: Streptococcus Bacteremia in Endocarditis, The Journal A. M. A., Oct. 2,

1915, p. 1159. 2 . Rosenow, E. C.: The Newer Bacteriology of Various Infections
2. as Determined by Special Methods, TrE Journal A. M. A., Sept. 12 as Determined transferred to eight centrifuge tubes containing sterile distilled water. The result of this step is the laking of the corpuscles and liberation of the hemoglobin. These tubes are immediately centrifuged at high speed, and the supernatant fluid subsequently pipetted off with a sterile pipet attached to a water suction pump. The sediment remaining in the bottom of the tubes is composed of the broken down hulls of the corpuscles together with any bacteria which may be present.

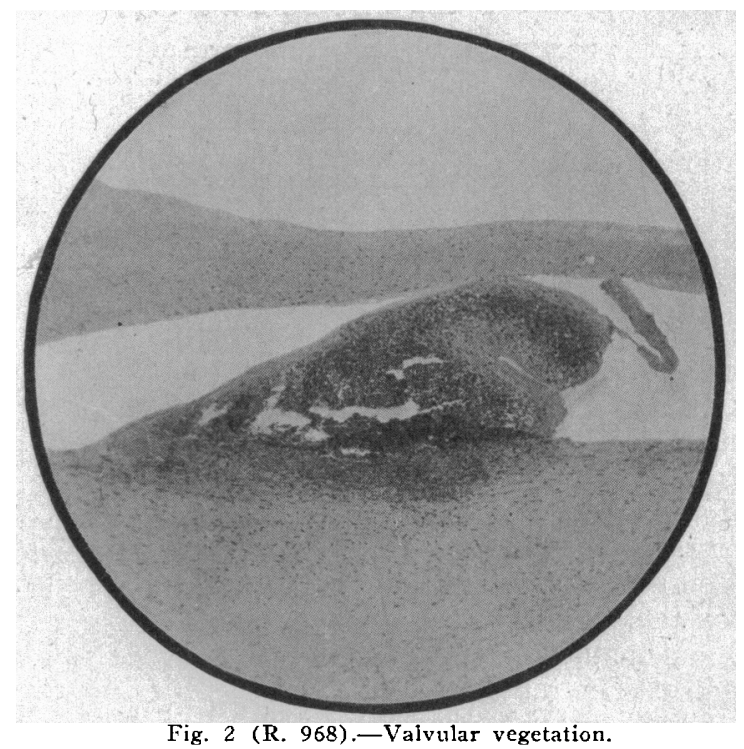

This operation is performed inside a glass cabinet which contains a Bunsen burner, the tube to the suction pump and the tap from the broth reservoir. By merely adding bouillon to the sediment, each centrifuge tube is converted into a culture flask, and is now ready to be placed in the incubator. The sediment of two tubes is reserved to be mixed with ascitic agar for

TABLE 1.-ACTION OF DIFFERENT STRATNS OF STREPTOCOCCUS VIRIDANS ON VARIOUS SUGAR MEDIUMS

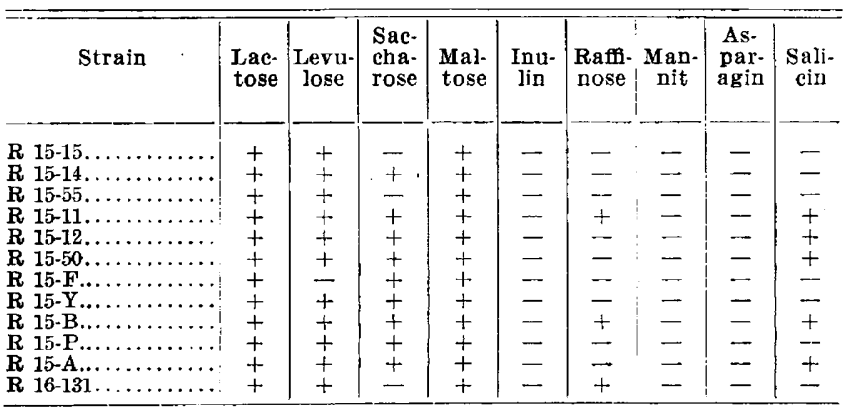

anaerobic conditions. This is obtained in a satisfactory manner by making this mixture after the agar has cooled to $40 \mathrm{C}$. and pouring into a tall test tube, the result being almost complete anaerobiosis at the bottom and a varying oxygen gradient as the top is approached.

The disadvantages of this method of blood culture are probably confined to two: The first is the time and skill required to carry out the technic, and this precludes its use as a routine measure. Such an objection, however, is not valid in a research laboratory. The second disadvantage is the large amount of unavoidable manipulation. Our only answer to that is the absence of contamination, which has given us the confidence we have in our results. 
The advantages are three: First of all, it seems reasonable that in a case in which the number of bacteria in the blood are few, the larger the sample taken, the more chance of obtaining the organism. Secondly, in chronic cases, such as we are investigating, it is believed that the patient has developed a certain amount of immune bodies in his serum. The provision in this method for the discarding of this immune serum will insure the organism having as little as possible to contend with. The serum removed is replaced by ascitic fluid from a patient who may reasonably be considered not to have an immunity to a streptococcus infection. In this way our medium is enriched by the necessary serum proteins without the danger of including inhibiting bodies. Lastly, the hemoglobin, which is said to have a detrimental effect on certain strains of streptococci, is largely removed.

The organisms used in this series of experiments vere obtained from blood in cases of subacute and chronic infectious endocarditis. All of the strains belong to the family of Streptococcus viridans, that is to say, while not all of them produced a distinct green on blood agar they resembled each other in their action on the various sugar mediums, and in their low grade of virulence. The minority, which were not green producing, yielded grayish fairly adherent colonies on blood agar; a few produced a brown color. All grades of chain formation, from very short to quite long forms, were found among them. They were usually arranged in pairs throughout the chain. They did not dissolve in bile salts. None of them fermented inulin. All produced acid and coagulation in lactose, maltose and levulose serum water. All but two acted in the same manner on saccharose. Fifty per cent. fermented salicin. Mannite and asparagin, as well as inulin, remained unchanged. The organisms are difficult to keep in stock, requiring to be transferred every two or three days. This is due to the inhibitory action of the acid which they produce on the glucose broth or agar used, the acidity going as high as 3 per cent., whereas the reaction of the mediums on which they are planted should not be higher than +0.5 . Latterly we have been making up the broth for stock cultures with 1 per cent. calcium carbonate, which insures the neutrality of the medium, and on this the organism lives for about seven days.

The animal experiments have been confined to an attempt to produce a condition in the rabbit analogous to that of the patient from whom the organism was obtained. The great difficulty of producing endocarditis experimentally, without previous injury to the valves, is well known. After unsuccessful attempts had been made, several observers succeeded in producing the condition by adding to the emulsion of organisms injected, a mechanical irritant. Among those investigators were Hibbert, ${ }^{3}$ who added potato particles, Orth and Wyssowitsch, ${ }^{4}$ and Fulci, ${ }^{5}$ who used pulverized charcoal. These foreign bodies produced a condition of erosion on the valve cusps, which thereupon became a favorable soil for the inflammation of

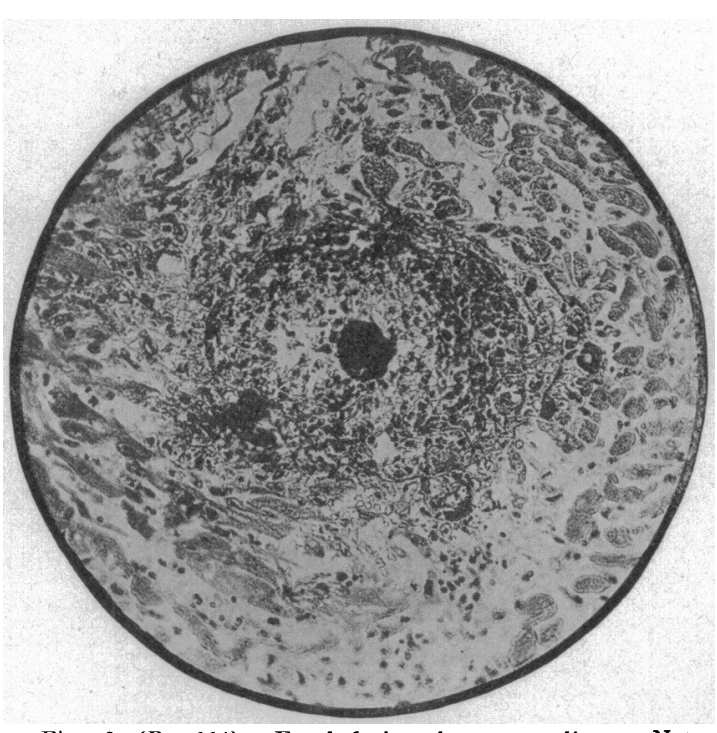

Fig. 3 (R. 664).-Focal lesion in myocardium. Note Fig. $3(\mathrm{R}, 664)$ - Focal lesion
blood vessel plugged with bacteria. the organism. Lissauer, ${ }^{6}$ Horder $^{7}$ Rosenow $^{8}$ and others have succeeded in producing endocarditis in rabbits without the aid of foreign irritants. The condition, of course, is produced with less difficulty with organisms of definite virulence. All are agreed on the fact that the streptococcus obtained in chronic infectious endocarditis is of very low virulence. Rosenow lays especial emphasis on this point. Believing that the strains of streptococci with which we were working were even less virulent than those which this author described, we were anxious to establish conclusive evidence of their ability to produce the disease in animals. Not only that, but we were equally anxious to learn whether these organisms of almost negligible virulence had nevertheless a special affinity for heart valves and the myocardium. We feel that

3. Hibbert: Fortschr. d. Med., 1886, iv, 1

4. Orth and Wyssowitsch: Virchows Arch. f. path. Anat., 1886, ciii 300,333 .

5. Fulci: Beitr. z. path. Anat., 1908, xliv, 349.

6. Lissauer: Centralbl. f. allg. Path. u. path. Anat., 1912, xxiii, 243. 7. Horder: Quart. Jour. Med., 1902, ii, 289.

8. Rosenow, E. C.: Jour. Infect. Dis., 1909, vi, 245; 1910, vii, 411 $429 ; 1912$, p. 210 ; Elective Localization of Streptococci, The Journat A. M. A., Nov. 13, 1915, p. 1687.

TABLE 2.-ACTION OF STRAINS ON RABBITS

\begin{tabular}{|c|c|c|c|c|c|c|}
\hline $\begin{array}{l}\text { No. of } \\
\text { Rabbit }\end{array}$ & $\begin{array}{l}\text { Strain of } \\
\text { Organism } \\
\end{array}$ & $\begin{array}{l}\text { No. and Amount } \\
\text { of Intra- } \\
\text { venous } \\
\text { Injection }\end{array}$ & Clinical Picture & $\begin{array}{l}\text { Death After } \\
\text { First } \\
\text { Inoculation }\end{array}$ & Postmortem Findings & Postmortem Cultures \\
\hline R. 518 & Stein.... & $\begin{array}{l}2 \text { medium } 1 \mathrm{~V} . \\
\mathrm{B}, \mathrm{C} .\end{array}$ & 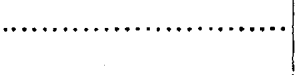 & 18 days...... & Liver, spleen and kidney congested..... & $\begin{array}{c}\text { Cultures from liver, } \\
\text { spleen and heart's } \\
\text { blood pure streptococei }\end{array}$ \\
\hline R. 125 & $15-55 \ldots \ldots \ldots$ & 2 small doses... & & 7 days........ & $\begin{array}{l}\text { No evidence of endocarditis; liver con- } \\
\text { gested; hydropericardium; pericarditis }\end{array}$ & $\begin{array}{l}\text { blood pure streptococei } \\
\text { cultures from liver, } \\
\text { heart's blood and per- } \\
\text { icardial cavity gave } \\
\text { streptococci }\end{array}$ \\
\hline R. 991 & $\begin{array}{l}\text { 15-55 from } R . \\
125\end{array}$ & $\begin{array}{l}10 \text { small doses; } \\
1 \text { large dose }\end{array}$ & $\begin{array}{l}\text { Last dose } 2 \text { V. } \\
\text { died early next morn- } \\
\text { ing }\end{array}$ & 92 days...... & $\begin{array}{l}\text { Heart muscles fiabby; heart muscle } \\
\text { shows numerous small scattered areas } \\
\text { of round cell inflitration; some peri- } \\
\text { vascular infltration; kidney focal } \\
\text { and diffuse nephritis; numerous cir- } \\
\text { cumscribed areas of round cell infil- } \\
\text { tration }\end{array}$ & $\begin{array}{l}\text { Cultures from spleen } \\
\text { and lung show Strep- } \\
\text { tococcus viridans }\end{array}$ \\
\hline
\end{tabular}


the results of our investigations 'have justified this belief.

Rabbits from 6 weeks to $21 / 2$ months old were used. The majority were Belgian hares. The cultures were grown in vaccine bottles of 60 c.c. capacity, containing about 40 c.c. of ascitic glucose bouillon. A copious growth was obtained in twenty-four hours, and the bottle was then centrifuged at high speed in a special trunnion cup, and the supernatant bouillon pipetted off. This operation can be done with such nicety that practically no free fluid is left with the bacteria, which are thereupon suspended in 2 or 3 c.c. of sterile saline solution and injected intravenously into the rabbit. Filling the syringe with the emulsion and expelling it through a small needle leads to the clumps being largely broken up. This is repeated several times, and a uniform emulsion results. The marginal vein of the ear was used invariably. Each strain of organism is studied first of all in regard to its virulence. The lethal intravenous dose is roughly estimated by injecting varying amounts of the emulsion into several rabbits. The average dose tolerated is the amount of emulsion obtainable from one to two vaccine bottles. This is an enormous dose of bacteria to be introduced directly into the blood stream of a rabbit weighing, say, 700 grams. When the lethal dose and the dosis tolerata are established, we try to keep the injections up to the highest point possible without killing the animal too quickly.

In Table 2, only a few of the cultures obtained are represented. It is impossible to give in this space the details relating to so many different strains. Those given, however, have been carefully chosen so as to be as representative as possible, and may be supplemented, if desired, by our records in the laboratory. Examples are described as showing a gradation of lesionsfrom ordinary streptococcic bacteremia without localization to cndocarditis of the malignant, ulcerative type. Cases $\mathrm{R}$ 518, R 521, R 516, R 968, R 341 and $R 665$ are, in the order named, examples of just such a thing. Cases R 125 and $R 281$ are good examples of pericarditis in the absence of endocarditis. There seems to be first of all an affinity for the heart valves and, failing this, the organism seems to pick out the pericardium, or, in a few instances, the myocardium. $\mathrm{R} 991$ is a case illustrative of the latter. Of all the rabbits coming to necropsy, heart lesions were found in $\mathbf{5 6 . 6}$ per cent. Endocarditis was present in 40 per cent., pericarditis in 13.3 per cent., myocarditis in 6 per cent., and aortitis in 3 per cent., while 30 per cent. gave a negative result. A slight degree of fever was present in all but one of the cases in which the temperature was taken. The average temperature of the rabbits with endocarditis was 103.8 , the temperature of normal rabbits being about 102.5 . These figures refer to readings by rectum. One case had a subnormal temperature - 100.8. Blood cultures were taken during life in a number of cases, but although the results are interesting they are necessarily inconclusive, since the measure was not carried out as a routine. It would seem, however, that, excepting in the later stages of the disease, it is fairly difficult to produce a constant bacteremia with the organisms under discussion.

With these data before us, we feel that we have successfully demonstrated that while the organisms recovered in clinical cases of chronic infections of endocarditis are of an exceedingly low grade of virulence, they are nevertheless capable of producing in the rabbit not only a condition closely resembling that of the patient from which they were obtained, but also a condition which often ends fatally, accompanied by the usual signs of acute ulcerative, or so-called malignant endocarditis. We are therefore inclined to believe with Rosenow ${ }^{9}$ that the ordinary Streptococcus viridans or "endocarditis coccus" may produce all grades of endocarditis, and every grade may be produced in animals by the different strains of the organism. We also have shown that every grade of endocarditis may be produced in different animals by the same strain of organism.

Some evidence is at hand supporting the theory of implantation. A rabbit, R 374, inoculated with Strain R. 15-131 presented at necropsy a verrucose vegeta-

9. Rosenow, E. C.: Experimental Endocarditis, Jour. Infect. Dis. 9. Rosenow,
September, 1912 .

TABLE 3.-ACTION OF STRAINS FROM NORMAL MOUTHS ON RABBITS

\begin{tabular}{|c|c|c|c|c|c|c|}
\hline $\begin{array}{l}\text { No. of } \\
\text { Rabbit }\end{array}$ & $\begin{array}{l}\text { Strain of } \\
\text { Organism }\end{array}$ & $\begin{array}{l}\text { No. and Amoun } \\
\text { of Intra- } \\
\text { venous } \\
\text { Injection }\end{array}$ & Clinical Pieture & $\begin{array}{l}\text { Death After } \\
\text { First } \\
\text { Inoculation }\end{array}$ & Postmortem Findings & Postmortem Cultures \\
\hline R. 664 & F. A.... & 2 V. B. C... & $\begin{array}{l}3 \text { days later very sick; } \\
\text { lies on fts belly with } \\
\text { all } 4 \text { legs extended } \\
\text { continually nodding } \\
\text { its head; temp. } 97 \mathrm{~F} \text {. }\end{array}$ & $\begin{array}{l}3 \text { days after } \\
\text { inoculation } \\
\text { ch lo ro. } \\
\text { formed }\end{array}$ & $\begin{array}{l}\text { Heart: Pericarditis, myocarditis; vege- } \\
\text { tations on the tricuspid valve, tip of } \\
\text { the papilary muscle and on the wall } \\
\text { of the right auricle; these show a } \\
\text { hemorrhagic area around them; one } \\
\text { small vegetation also on the pulmo- }\end{array}$ & $\begin{array}{l}\text { Culture from the blood } \\
\text { s h o } \mathrm{s} \text { streptococei, } \\
\text { culture from pericar- } \\
\text { dial cavity sterile }\end{array}$ \\
\hline R. 573 (1) & $\begin{array}{l}\text { Peq; rrom } \\
\text { a normal } \\
\text { throat }\end{array}$ & $\begin{array}{l}3 \text { injections; } \\
24 / 2 \text { V. B. C. }\end{array}$ & $\begin{array}{c}\text { After first injection, } \\
\text { temp. } 106 \mathrm{~F} .\end{array}$ & 7 days........ & $\begin{array}{l}\text { nary artery } 3 \mathrm{~mm} \text { above the valves } \\
\text { Heart: Myocarditis present; } 1 \text { large } \\
\text { verrucose vegetation of the tricuspid } \\
\text { valve, involving all the cusps and ex. } \\
\text { tending down on to the wall of the } \\
\text { heart; } 1 \text { small vegetation on one of } \\
\text { the cusps of the aortic valve }\end{array}$ & $\begin{array}{l}\text { Cultures: heart's blood } \\
\text { and liver, Streptococ- } \\
\text { cus viridans }\end{array}$ \\
\hline
\end{tabular}


tion on the free edge of the valve. The microscopic examination of this specimen reveals no signs of capillary connection with this vegetation, and gives every appearance of its being merely an implantation on the edge of a valve which has been subjected to the constant erosive action of the intimate but intermittent pressure of its fellow. The fact that in the same rabbit there is found a similar vegetation at the base of the valve, or on the valve ring, does not necessarily

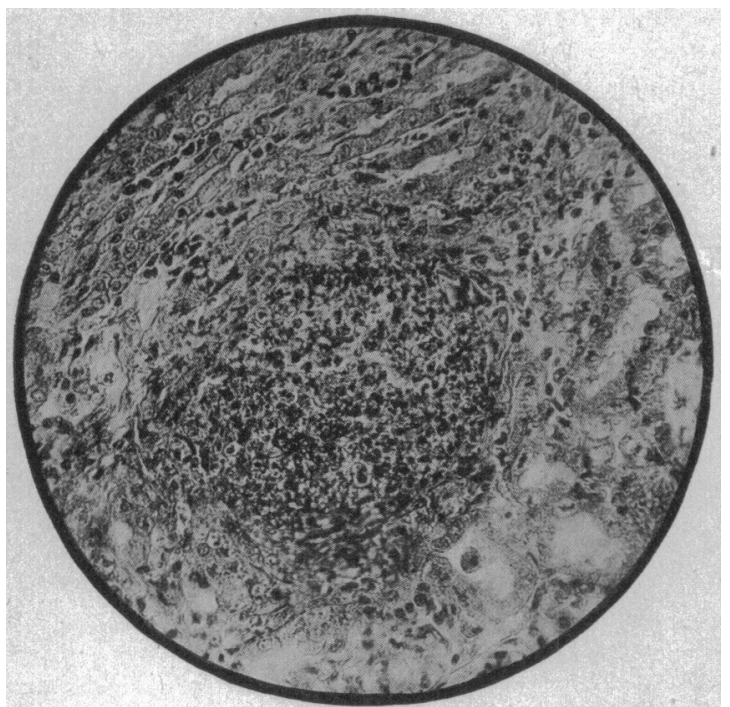

Fig. 5 (R. 574).-Focal lesion in kidney.

disprove or even cast doubt on the implantation theory, especially in view of the fact that the site of the vegetation is on the auricular side of the valve. What does seem to favor the embolic theory, however, is the finding of hemorrhages in the valve curtains and under the mural endothelium, as the earliest evidence of the work of the bacteria, or bacterial emboli. Cultures of streptococi can be obtained from these areas, and it is quite likely that on this favorable medium they begin the process which results in the familiar vegetation.

The clinical picture of the rabbit with chronic endocarditis resembles in a striking manner that of the patient with the same condition. The low grade of fever seenis to be a constant feature of the disease, with periods of no fever, and bacteria-free blood stream. The fact that patients known to have endocarditis do not constantly yield positive blood cultures is, of course, well recognized. In the light of our findings there is no doubt in our minds that if we only had a way of knowing the opportune time, we might recover the streptococcus from the blood in many of these cases which now yield negative results. There is every reason to believe that the presence of streptococci in the blood does not necessarily mean, as was formerly supposed, a fatal issue. Rabbits from which we obtained positive blood cultures apparently, some in recovered cases, lived for months, and when chloroformec', yielded negative results at necropsy. Similarly, in clinical cases with bacteremia there has been improvement, and no doubt the animals will entirely recover. The loss in weight of the rabbits with endocarditis was another noticeable feature of the clinical picture, which also corresponds with the findings in the human types. In some cases the emaciation was quite marked and, at least to some degree, seems to be a constant feature in the animals.

It is exceedingly interesting to note the evident elective localization on the heart, and especially on the heart valve of these strains of streptococci, whose habitat was the heart valve and blood stream of their human host. Injected into the vein, they are pumped immediately into all parts of the body. Why do they not localize in the kidney, the appendix or the joints? Case R 281 was inoculated with a culture from the pericardial cavity of $\mathrm{R} 9780 \mathrm{~S}$ with pericarditis. The necropsy next day revealed marked hemorrhages into the pericardium, and the pericardial surface of the heart was definitely inflamed. Yet the heart valves were perfectly normal. Surely there is something uncanny about the way in which these interesting organisms select their own peculiar scene of activity. Possibly much lies hidden in the expressions "elective localization" and "affinity," with which we dismiss these interesting phenomena from our discussions.

The similarity between the organisms recovered from the blood and the streptococci usually found in the tonsils and mouth of normal individuals is worthy of note. This is to be noted not only in the sugar reactions but also in animal experiments. Nor is this similarity at all surprising. If we believe, as we assert, that the Streptococcus viridans passes through the diseased tonsil, suppurating alveolar socket, or other favorable lesions of the buccal and pharyngeal cavities, and, entering the blood stream, localizes on the heart valves, is it to be wondered at that the similarity to the saprophytic relative still living in the mouth should be at least outstanding enough to be noticeable? We felt that it was altogether likely that these saprophytic streptococci living in the normal mouth could be proved to have the power to produce endocarditis in an identical manner to that of the organisms described in the foregoing experiments, and we inaugurated plans to carry on at once the necessary experiments to determine this point.

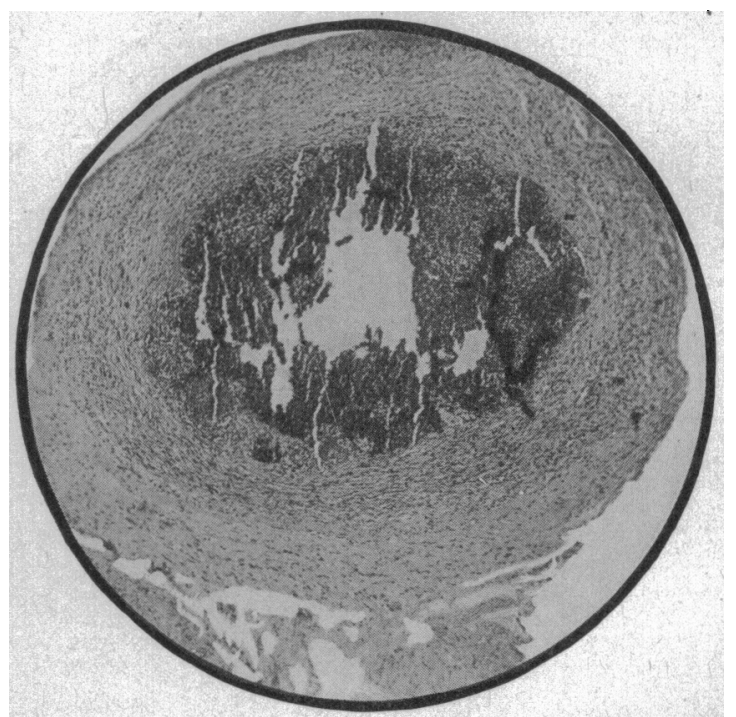

Fig. 6 (A. 374).-Section of vegetation.

Both Horder ${ }^{10}$ and Rosenow ${ }^{9}$ have reported the successful production of endocarditis in rabbits from streptococci isolated from normal saliva (Horder) and tonsils (Rosenow). Their experiments, however, were very limited, and no attempt was made to issue accurate statistics. Our series, while larger, is not as comprehensive as we should have liked. Still, as far as it goes, it is quite conclusive. The cultures for this

10. Horder: Quart. Jour. Med., April, 1909; Local Gov. Rep., 
series of experiments were obtained from the teeth, gums and tonsils of medical students in the bacteriologic classroom. Eleven strains in all were used, and thirty-one rabbits were inoculated. The technic followed was identical with that used in the experiments recorded in the earlier part of the paper. All the strains were of the viridans variety of streptococcus. That is to say, they were capable of producing green on blood agar, gave typical fermentative reactions on

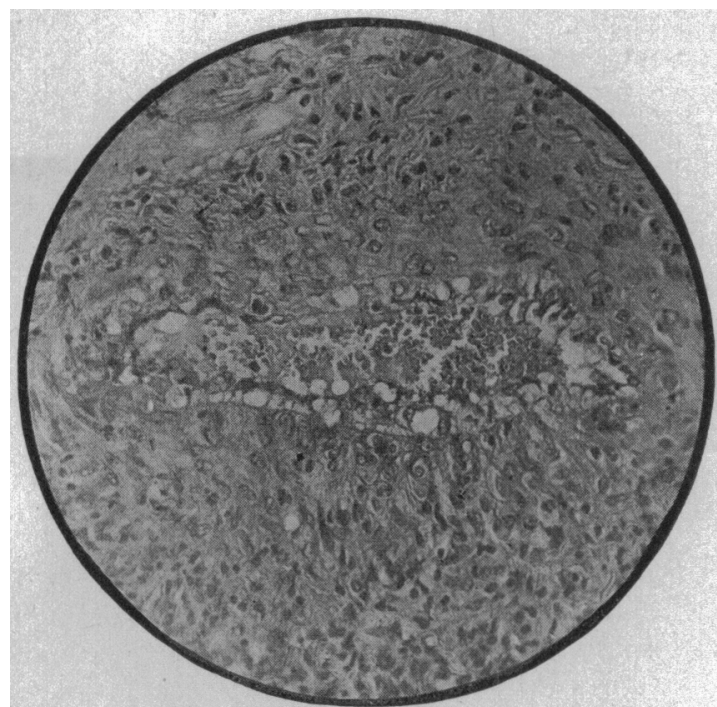

Fiy. 7 (R. 374).-Reaction about blood vessel just beneath endo cardium, which was bulging at this point. Probably early stage of mural vegetation.

the various sugars, and their other cultural characterisiics were typical. They did not ferment inulin. Heart lesions of one kind or another were present in 80.6 per cent. of the rabbits. Of these, myocarditis came first with 67.7 per cent., and endocarclitis next with 58 per cent. Aortitis was present in 32 per cent., and pericarditis was found in 22.5 per cent. Arthritis was demonstrated in 12.5 per cent.

It will be seen (Table 3 ) that the percentage of positive results in connection with the mouth and throat series is greater than that of the series from strains recovered from the blood. This may be accounted for by the fact that subcultures were made of some of the latter several times before the first inoculation was made, whereas in the former, owing to increased facilities, we were able to begin inoculations from the first and second subculture, or as soon as pure culture was obtained. This discrepancy was true in only a few cases, however, and the presumption is that the organisms, after reaching the blood, remain as avirulent as those which are left in the mouth.

The proportion of myocarditis is high, and evidently no higher than it should be. Although cloudy swelling and fatty degeneration were counted as myocarditis, the great majority had also focal areas of infiltration with round cells, and, less frequently, with polymorphonuclear cells. There were a great number of sections made in those cases showing on casual examination no focal lesions, and careful study given them. It seems likely, from our findings, that the presence of these focal areas would be demonstrated in some hitherto considered negative.

The fact that none of the strains isolated from the blood in cases of endocarditis produced joint lesions, whereas definite arthritis was present in four cases from strains isolated from the mouth and tonsils, seems significant to us. It strongly suggests two possible explanations: First, that an organism may have in some instances a dual affinity, and depending on environment and conditions existing in the particular individual in which they are present, they may attack one organ, or another, or both. Second, and more likely, that two types were present in one culture and each type produced its respective lesion. Pure cultures only of Streptococcus viridans were sought, and on being obtained, no attempt was made to grow the organism from one colony alone. When we speak of dual affinity, the term must of course be taken in its broad application. We all know that practically every pathogenic organism can attack a variety of structures. That is not what is meant. But just as the pneumococcus has a special predilection for the respiratory tract, though it does produce lesions elsewhere, and in the same way the meningococcus for the meninges, so the Streptococcus viridans confines itself to the heart, or to the joints, or, as we suggested above, to both. It seems plain from our findings, at any rate, that the type of strain in the mouth and throat has a great deal to do with the type of lesion the patient is liable to develop. Take for example the results in respect to aortitis. The regularity with which this condition, in conjunction with endocarditis, was produced by certain strains is very striking. Strains L-7 and M-8 yielded aortitis in every instance. Strain M-8 was inoculated into six rabbits, and definite aortitis resulted in all.

Although the Streptococcus viridans usually produces chronic lesions, in which round cells greatly predominate, it can attract leukocytes in relatively large numbers, and therefore produce microscopic abscesses. Sections of vegetations show a small area in the center, composed chiefly of polymorphonuclear leukocytes with some of the nuclei undergoing fragmentation. There are also present some lymphocytes. Surrounding this focal mass of cells there is an area of proliferating endothelial cells. Some of the older vegetations show fatty changes with calcareous deposits in the center.

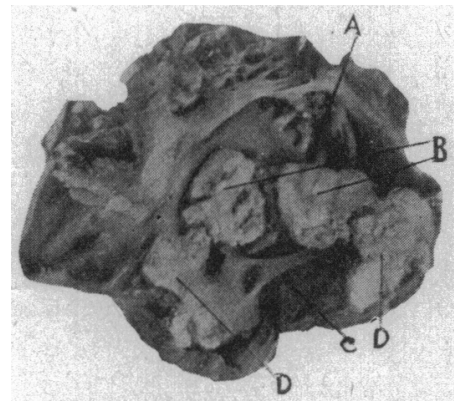

Fig. 8 (R. 341).-A, right auric'e; $B$, vegetations on tricuspid valves; $C$, right ventricle; $D, D$, cut surfaces of same vegetation.

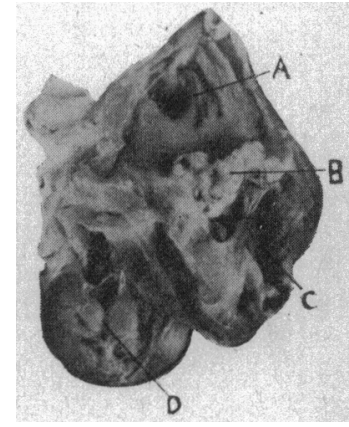

Fig. 9 (R. 665).-A, right auricle; $B$, vegetations on tricle; $D$, left ventricle.
The focal areas in the heart muscle generally surround a small blood vessel which is completely occluded by a bacterial embolus. There is a necrosis of the muscle fibers, and a round cell infiltration composed of both polymorphonuclear leukocytes and lymphocytes.

\section{CONCLUSION}

Let us venture to suggest that we have established three important points:

1. The Streptococcus viridans, isolated from the blood in cases of chronic infectious endocarditis, is of 
very low virulence, probably lower than any hitherto reported as being recovered from a similar source.

2. These streptococci are capable of producing lesions in animals identical to those found in the patients from whose blood the organisms were obtained.

3. The strains of Streptococcus viridans isolated from the mouth of normal individuals are similar to those isolated from the blood of patients suffering from chronic endocarditis, and are equally capable of producing heart lesions in the rabbit.

\section{USE OF PARTIAL VACUUM IN DIAGNOSIS AND TREATMENT * \\ HARVEY G. BECK, M.D. \\ BALTIMORE}

AN APPARATUS DESIGNED FOR THE

Many of the old time appliances used in methods of diagnosis and treatment based on the principle of suction are very unsatisfactory. This is especially true of those methods in which suction is obtained by means of rubber bulbs, such, for example, as the Boas and Ewald methods for aspirating stomach contents, Bier's hyperemia and the breast pump. Among the most striking objections may be mentioned the lack of durability, the inconstancy of suction force and the inability to measure the degree of suction employed.

Similar objections prevail when the various aspirating pumps or syringes are used. In the Potain apparatus, no provision is made for estimating the degree of vacuum, and there is always the danger of inad-

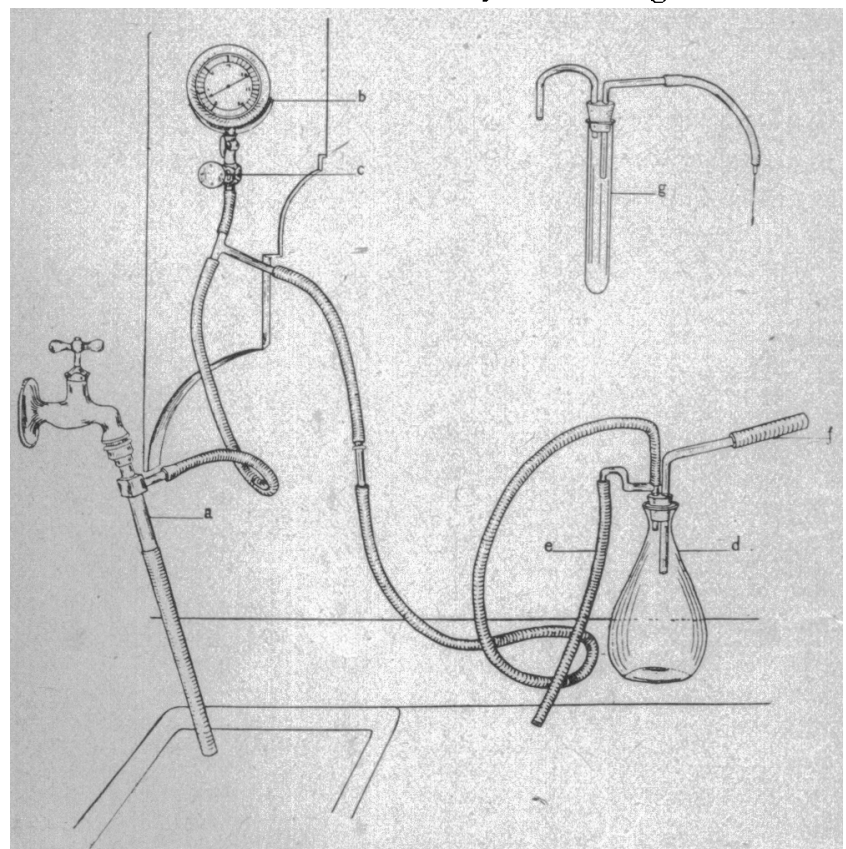

Fig. 1.-Partial vacuum apparatus: $a$, filter pump; $b$, vacuum gage; $c$, vacuum regulator; $d$, wash bottle for collecting stomach contents; $e$, connecting tube with which to cut of the air and release the vacuum blood for Wassermann test.

vertently forcing air into the pleural cavity, as I have seen happen. Moreover, there seems to be no other apparatus quite as prone to get out of commission as the aspirating pump. It was, therefore, a matter of

* Read before the Section on Pharmacology and Therapeutics at the Sixty-Seventh Annual Session of the American Medical Association, Detroit, June, 1916. expediency which led me to employ the principle of suction in the form of a simple, inexpensive vacuum apparatus (Fig. 1).

This consists of a filter pump connected by means of heavy rubber tubing with an ordinary vacuum gage which is provided with an adjustment for regulating the degree of vacuum. Any degree of constant suction a s expressed in inches of mercury may thus be obtained, or, by the use of a release valve or cut-off, the suction can be interrupted. The steady constant suction is employed in aspirating stomach contents, pleural eff us ions, bloodletting, et c., and the interrupted in Bier's hyperemic cupping, breast pumping, etc.

\section{APPLICATION OF METHOD \\ Aspirating Stom- ach Contents.-} For this purpose an ordinary wash bottle (500 c.c. Erlenmeyer flask) is attached to the apparatus, which is adjusted for a vac-

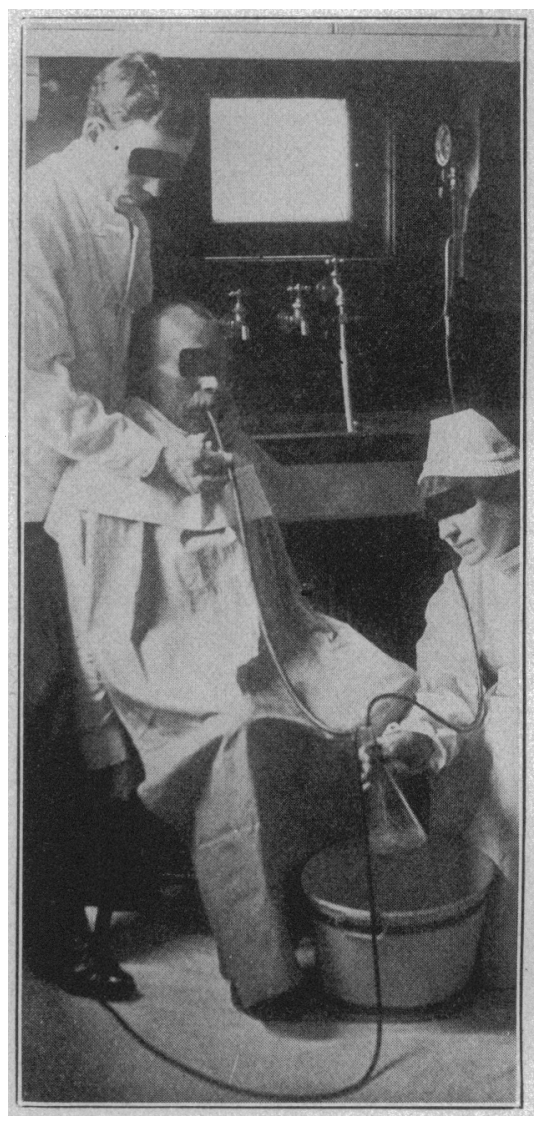

Fig. 2.-Method of aspirating test meals. uum of 5 inches of mercury. A large stomach tube is connected with the wash bottle and also a long piece of rubber tubing, one end of which rests on the floor. Suction' is started by compressing the tubing on the floor with the foot, and released by removing the foot. Both hands are thus free to manipulate the stomach tube (Fig. 2).

Several hundred test meals have been extracted in this manner and many fasting stomachs aspirated for hypersecretion and residual contents.

It has been conclusively demonstrated by routine lavage following aspiration that the Mayo test meal, which consists of six arrowroot biscuits, one glass of hot water and one glass of cold water, can be completely removed by this method. This is also true of the secretions in a fasting stomach. These features are of tremendous value in ascertaining the actual motor and secretory functions of the stomach-data of extreme clinical importance.

As a therapeutic measure it has a great advantage over lavage by siphoning, especially in those cases in which large amounts of mucus are present. After the usual method some mucus remains in the stomach, even after repeated washing, but this can readily be removed by the partial vacuum apparatus with the use of a large tube and wash bottle.

In fractional gastric analysis with the Rehfuss tube the partial vacuum method is particularly applicable as 